\title{
Lost in Transmission: Testimonial Justification and Practical Reason
}

\section{Andrew Peet and Eli Pitcovski}

\begin{abstract}
Transmission views of testimony hold that the epistemic state of a speaker can, in some robust sense, be transmitted to their audience. That is, the speaker's knowledge or justification can become the audience's knowledge or justification via testimony. We argue that transmission views are incompatible with the hypothesis that one's epistemic state, together with one's practical circumstances (one's interests, stakes, ability to acquire new evidence etc.), determines what actions are rationally permissible for an agent. We argue that there are cases where, if the speaker's epistemic state were (in any robust sense) transmitted to the audience, then the audience would be warranted in acting in particular ways. Yet, the audience in these cases is not warranted in acting in the relevant ways, as their strength of justification does not come close to the speaker's. So transmission views of testimony are false.
\end{abstract}

Keywords: Testimony; Transmission; Pragmatic Encroachment; Testimonial Justification

\section{Background}

Transmission views of testimony maintain that epistemic states can be transmitted between agents.

That is, they hold that when an agent acquires testimonial knowledge or justification through accepting a speaker's testimony they do so by acquiring someone else's (standardly the speaker's) knowledge or justification (Burge 1993, 1997, Faulkner 2010, Hardwig 1985, 1991, McDowell 1994, Owens 2000, 2006, Schmitt 2006, Welbourne 1986, Williamson 2000, and Wright 2016).

Transmission views have not gone unchallenged. They have been the subject of attacks by Lackey (1999), and MacFarlane (2005). However, these objections have been limited in scope. Rather than targeting the general notion that epistemic states are transmitted from speaker to hearer they target the notion that one specific epistemic state, knowledge, is transmitted via testimony. According to MacFarlane, given subject sensitive invariantism, standards for knowledge may depend on pragmatic circumstances, so an audience can fail to have knowledge even if they inherit the purely epistemic aspects of the speaker's belief (MacFarlane (2005: 134)). According to Lackey, an audience can sometimes gain knowledge that $p$ which the speaker does not possess. However, the subject in Lackey's cases still possesses justification to believe $p$. Thus, as Wright (2016) points out, it is compatible with Lackey's cases that the agent's justification is transmitted. 
Both objections fail to target the core notion that epistemic states are transmitted from speaker to hearer. Transmission theorist can make the correct predictions if they focus on justification transmission and slightly revise their notion of knowledge transmission.

The target of our objection is the transmission theorist's core thesis. There are cases in which if the hearer were to inherit the speaker's epistemic state (or certain aspects of the speaker's epistemic state, such as their justification or knowledge), then they would be justified in acting upon it. However, they are not justified in acting upon that epistemic state. Thus, in these cases, hearers fail to inherit the epistemic aspects of the speaker's belief. ${ }^{1}$ Our argument will focus on the notion of justification transmission, but the cases we present are equally problematic for knowledge transmission.

\section{$\underline{\text { Against Transmission }}$}

Central to the transmission hypothesis is the idea that in many cases of testimonial knowledge or justification the audience, in a very substantive sense, receives the speaker's knowledge or justification. As transmission is standardly understood, this is an all or nothing affair (see Wright 2014). ${ }^{2}$ For the transmission theorist, unless the audience possesses a defeater ${ }^{3}$ the audience's strength of justification will match the speaker's. This assumption will play a key role in our argument against transmission, which is as follows:

1 In a sense our point is the converse of MacFarlane's. Macfarlane presents cases in which, even if epistemic properties were transmitted, the audience would not know. We present cases in which, if epistemic properties were transmitted, the audience would be justified in acting.

2 Though Wright (2014) and Faulkner (2000: 591) are the most explicit, it is trivially implied by other transmission views. For instance: Owens (2006: 120) and Schmitt (2006) agree that the audience's belief will be based on "the very grounds" on which the speaker's belief is based (although we will later suggest that Schmitt at least has the resources to adopt a weaker version of the transmission thesis according to which only part of the speaker's justification is transmitted). Burge (1993: 465) compares transmission to memory which, in turn, "simply maintains in justificational space a cognitive content with its judgmental force". And McDowell (1994) holds that when one testifies one puts into the public domain (and thereby makes available to others) one's standing in the space of reasons.

3 Or unless practical factors (such as the stakes) affect justification. Our argument accounts for such factors. 
Premise 1: If one is deliberating about whether or not to preform $\mathrm{H}$ (some high-stakes course of action) and some proposition $p$, for which one has very little evidence, is decisive for the correct decision with respect to $\mathrm{H}$, then if 1 . One is told that $p$ by a first expert, and 2 . One is aware that there is a second expert immediately available for a second opinion with an extremely low cost, then one should obtain the second opinion before one acts. This is illustrated by the following case:

Medical Opinion I: A team of doctors have narrowed down your condition to one of two: Either you have Condition-A or you have condition-B. The treatment for condition-A is the amputation of one arm. The treatment for condition-B is the amputation of one leg. Both conditions are such that if you don't get treated within one month, both of your arms and both of legs will fall off. Finally, after running the relevant tests, each doctor is available to deliver their verdict. You know each doctor is respected, and you have no reason to believe they will disagree, but you also don't know that they will agree. The first doctor you consult says "you have condition-A, you should have your arm amputated". It seems irrational for you to go straight to surgery and have your arm amputated without hearing what the doctor in the next room has to say. ${ }^{4}$

Premise 2: The amount of justification necessary/sufficient for one to rationally act on a belief that $p$ varies with the stakes (and other practical factors). When the stakes for agent A (with respect to $p$ ) are higher than the stakes of another agent $\mathrm{B}$, and $\mathrm{A}$ and $\mathrm{B}$ are identical in all other practical respects (e.g. in the availability of further evidence), the amount of justification sufficient (for acting on $p$ ) for A cannot be lower than the amount of justification sufficient for B (to act on $p)^{56}$.

4 Anderson (2015) and Anderson and Hawthorne (forthcoming) present similar cases and share our verdict about the impact of practical factors such as additional available evidence on the rationality of action.

5 This principle is closely related to the following principle:

Stakes Dependence: when the stakes for agent A (with respect to p) are higher than the stakes of another agent B, the amount of justification necessary/sufficient (for acting on $\mathrm{p}$ ) for A cannot be lower than the amount of justification necessary/sufficient for B (to act on $\mathrm{p}$ ). 
Premise 3: From justification transmission views of testimony, together with premise 2 it follows that:

Degree Transmission: if a speaker is practically situated with respect to $p$ in such a way that acting on $p$ requires very-strong justification, yet they nonetheless have enough justification to act on $p$, then if they assert $p$ to an audience who is practically situated in such a way that a lower degree of justification (merely strong justification) is required for action and the audience is otherwise practically situated in a parallel way to the speaker, then the audience thereby acquires enough justification to act on $p$ (assuming that the audience has no defeaters).

Premise 4: Degree Transmission is inconsistent with Premise 1. This is illustrated by the following case:

Medical Opinion II: Picture the case given in support of premise 1. However, add to it that your father is a mob boss and will assassinate any doctor who recommends the wrong treatment (since your father knows you either have condition-A or condition-B it will be easy for him to tell when the wrong treatment was carried out). The doctors know this. Thus, the stakes are extremely high for the doctors, even higher than they are for you. Nonetheless

\footnotetext{
Stakes Dependence is called into question by Anderson (2015), and Anderson and Hawthorne (forthcoming), who argue that practical factors other than the stakes can intervene and affect the amount of justification required for permissible action. Our principle allows for such factors . To deny our principle would have amount to maintaining that epistemically permissible action depends on factors other than the agent's justification and their practical situation.

6 This principle may fail in some cases of 'isolated second hand knowledge' (see Lackey 2010). However, isolated second hand knowledge only seems problematic when there is an expectation that we act only on first-hand knowledge. There is not such expectation in Medical Opinion 1: One seeks medical advice because one lacks the means and expertise to investigate one's condition oneself. Moreover, if the second opinion were not available then the audience would surely be warranted in acting on the first doctor's advice. This indicates that it is not the isolated and second hand nature of the testimonial belief which renders it unable to warrant action.
} 
the first doctor has studied your condition intensively. She has spent the whole year analyzing every feature of your condition, your background, and your family. She has run all the tests that can be run. And she has read every relevant journal article. Every ounce of evidence points toward you having condition-A. Although it is possible for her to seek a second opinion, we can imagine that the body of evidence she possesses is so overwhelming that this is not necessary. She is thus sufficiently justified to confidently assert, even in these circumstances, that you have condition-A. Indeed, given the overwhelming amount of evidence she possesses, it seems she can do so without asking for a second opinion from one of the other available doctors. In asserting that you have condition-A she is, in this case, acting on her belief that you have condition-A. ${ }^{7}$ If, upon accepting her testimony (believing on the basis of her testimony that you have condition-A) you acquire her justification, then you too should be in an epistemic position to act on $p$ without seeking a second opinion. Nonetheless, since the second opinion is available at absolutely no cost, and since you do not know about the huge amount of work the first doctor has done, ${ }^{8}$ it still seems irrational for you to go straight to surgery without at least hearing the second opinion. ${ }^{9}$

Conclusion: Transmission views of testimony are false. ${ }^{10}$

7 It is not obvious that assertion and knowledge have the same norm, nor that one is always acting on a belief that $p$ when one asserts that $p$. Nonetheless, in this case the doctor is, in asserting that $p$, acting on her belief that $p$.

8 This is not to say that you do not have reason to trust the doctor. Rather, it still seems irrational for you to act on the acquired belief without seeking a second opinion. Thus, the problem isn't that you are not positioned to accept the testimony, rather the problem is that the belief you form upon accepting the testimony does not have the same epistemic status as the doctor's belief

9 It is important that you do not know about the doctor's stakes, or their overwhelming body of evidence. Otherwise you might not be obligated to seek a second opinion.

10 This argument is, of course, also problematic for knowledge transmission. If knowledge is sufficient for action then the patient should receive the doctor's knowledge and be warranted in acting. Yet they are not warranted in acting. If knowledge is not sufficient for action then we need an account of what more is required. This additional factor would have to vary between the doctor and the patient. Given the parallels between the practical situations of the doctor and patient it is hard to see what the additional factor could be. 
One might question our intuitions about the case. Firstly, given that they have the word of an expert they trust, one might question whether the patient must really ask for a second opinion despite its immediate availability. To strengthen the intuition that one must acquire a second opinion

\section{$\underline{\text { Objections }}$}

1. As we noted, justification transmission is standardly treated as an all or nothing affair. In response to the above, transmission theorists might deny this, and maintain that only part of the speaker's justification is transmitted. Consequently, they can get the right prediction (that the audience does not acquire the amount of justification required for action). In order for this response to have any bite we are owed a story about the determinants of what is transmitted in a given case. Without such a story it is unclear what to make of the transmission theorist's claim that audiences inherit, in a substantive way, the speaker's justification.

To complete their response, transmission theorist might, for example, hold that only the justification which constitutes the basis for the speaker's assertion is transmitted, or that the audience's belief only gains support from those reasons without which the speaker would not have made their assertion. ${ }^{11}$ However, our argument can be extended respectively to meet such modified views. It need only be stipulated that the speaker asserts on the basis of their total body of justification, or that the speaker only just met the threshold for rational assertion, meaning that they would not have asserted had any of their reasons been absent. This would make the audience's belief counterfactually dependent on the speaker's total body of reasons. It is unclear how any weakened transmission hypothesis can avoid mirroring-modifications of Medical Opinion 2 whilst remaining in the spirit of the transmission hypothesis.

2. The transmission theorist could simply deny that one is obligated to seek a second opinion in Medical Opinion 2. They might argue that one is not always in a position to know one's level of justification, and thus one is not always in a position to know what actions one can permissibly

11 Schmitt (2006) can be seen as advocating such a view. 
undertake. In Medical Opinion 2 one can permissibly go straight to surgery, but one does not know this.

We do not wish to hold that agents are always in a position to know their precise level of justification, or the precise courses of action they can permissibly undertake. However, it seems extremely implausible that the agent is permitted to act in Medical Opinion 2. There are two ways to bring this out. Firstly, consider a third-person version of our case: If a companion consulted with the doctors, and decided on the treatment for the patient, it would be justified of the patient to blame that companion for acting recklessly if, despite the easy availability of a second-opinion, they decided to base their decision on the opinion of the first expert they heard. It is hard to see why this would be if the doctor's testimony was sufficient to warrant action in these circumstances.

Secondly, the stakes in Medical Opinion 2 can be manipulated to be arbitrarily high. For example, suppose that the cost of the wrong treatment is not the loss of some limbs, but rather eternal torture in hell. We can imagine that the risk for the doctor is eternal torture in a slightly worse bit of hell, and that the doctor's justification is substantial enough to warrant assertion even in these circumstances. The transmission theorist would be forced to maintain that the patient should pursue the treatment simply on the basis of the doctor's recommendation, even in these circumstances. This seems extremely implausible.

3. The transmission theorist could perhaps respond by holding that the availability of a second opinion constitutes a defeater. There are two ways this response could go.

Firstly, the availability of a second opinion might be treated as a reason to withhold belief (Schroeder (2012)). In this case, it would be weighed against the speaker/audience's total body of justification, and play a role in determining their strength of justification. If the second opinion was only available to the audience then the audience's level of justification would be lower than the doctor's, since they have a reason to withhold. However, we postulated that this is not so. The 
second opinion is also available to the doctor, but the doctor's mass of evidence is so great that it outweighs their reasons to withhold, even given their stakes.

One might insist that, since the second opinion is available to the doctor, they too should refrain from acting. The reasoning here would require that one must always seek a second opinion when one can. Otherwise the doctor's evidence can be shifted to meet the threshold above which one needn't seek a second opinion. We find this line of response unpersuasive. We think it is clear that agents can be epistemically saturated: one's evidence can be strong enough that one needn't seek further evidence, even if one can do so at very little cost. As we constructed the case, the doctor seems epistemically saturated. If the patient inherited the doctor's epistemic state, they too would be epistemically saturated. However, it doesn't seem one can achieve epistemic saturation simply by accepting the testimony of a single doctor.

Secondly, the transmission theorist could point to the distinction between justification and entitlement, maintaining that in order to inherit the speaker's justification the audience must be entitled to accept their testimony (Burge (1993), Faulkner (2000) and Owens (forthcoming)). They could then maintain that the availability of a second opinion defeats the audience's entitlement to accept the doctor's testimony, thus preventing them from ever inheriting the doctor's justification in the first place.

This version of the defeat response can be deflected with only a small modification of our argument: We can modify Medical opinion 2 such that you are only told about the availability of a second opinion after you receive the first doctor's testimony. In this situation your entitlement to accept the doctor's testimony would not be defeated when testimony takes place, so you would acquire the doctor's justification. (It seems clear that if, as far as you are aware, the first doctor's testimony is all you have to go on, then you are warranted in acting on it). Yet it seems clear that once it becomes an option, you should, nonetheless, seek the second opinion before acting. So both versions of the objection fail. 


\section{Conclusion}

The case against transmission views rests solely on the minimal assumption that rational action depends on one's epistemic state in combination with one's practical circumstances. We have seen that in some cases, despite the practical circumstances being relevantly parallel, a speaker and an audience are not equally within their rights to act on the content of the testimony. Hence, contrary to what transmission views tell us, their epistemic states must be different. The thing that sets transmission theorists apart from other theories here is precisely their core claim: that the speaker's justification or knowledge becomes the audience's justification or knowledge.

We see two ways for the transmission theorist to avoid our argument: firstly, a radical reconceptualization of the relationship between action, one's epistemic state, and one's practical circumstances. Secondly: a radical re-conception of the relationship between the grounds for one's justification to believe, and the grounds for one's level of justification. We usually think of justification as closely tied to notions such as rationality and the normativity of action. However, the considerations presented here suggest that the transmission theorist must sever the connection between justification and permissible action. Other recent critiques of justification transmission (for example Barnett (2015)) put pressure on the connection between the transmission theorist's notion of justification and internalist rationality. Without a connection to rationality or permissible action it is unclear what content or theoretical interest remains in the transmission theorist's notion of justification. Thus, until the requisite re-conceptualizations are provided transmission theories must be treated with skepticism. ${ }^{1213}$

12 It might be worried that this argument is problematic for most theories of testimony: If one has reason to trust a speaker, and no reason to distrust them, and the speaker says that $p$, then one has reason to accept $p$. This may seem to imply that in the cases discussed so far, one would be rational in acting upon the first doctor's opinion without consulting a second doctor. But this is fallacious. This further verdict depends on the relationship between the epistemic state brought about by acceptance of $p$ and the norm of action. For instance, if one merely took justified belief (not knowledge) to result from justified acceptance, and at the same time took knowledge to be the norm of action, then one could avoid the prediction that one is justified in acting without seeking a second opinion (there are many similar options here). Secondly, one can avoid the implication by embracing pragmatic encroachment on justification, a move which does not seem available to the justification transmission theorist. 


\section{Bibliography}

- Anderson, C. 2015. On the intimate relationship of knowledge and action. Episteme 12: 343353.

- Anderson, C. and Hawthorne, J. Forthcoming. Knowledge, practical adequacy, and stakes. In Oxford Studies in Epistemology Volume 6, ed. J. Hawthorne and T. Gendler. Oxford: Clarendon Press.

- Barnett, D. 2015. Is memory merely testimony from one's former self? Philosophical Review 124: 353-392.

- Burge, T. 1993. Content preservation. Philosophical Review 102: 457-488.

- Burge, T. 1997. Interlocution, perception, and memory. Philosophical Studies. 86: 21-47.

- Fantl, J. and McGrath, M. 2002. Evidence pragmatics, and justification. Philosophical Review 111: 67-94.

- Faulkner, Paul. 2011. Knowledge on Trust. Oxford University Press.

- Hardwig, J. 1985. Epistemic dependence. Journal of Philosophy 82: 335-349.

- Hardwig, J. 1991. The role of trust in knowledge. Journal of Philosophy 88: 693-708.

- Lackey, J. 1999. Testimonial knowledge and transmission. The Philosophical Quarterly 49: 471-490.

- Lackey, J. 2010. Acting on knowledge. Philosophical Perspectives 24: 361-382.

- MacFarlane, J. 2005. Knowledge laundering: testimony and sensitive invariantism. Analysis 65: 132-138.

- McDowell, J. 1994. Knowledge by hearsay. In Knowing from Words, ed. B. Matilal and A. Charkrabarti, 195-224. Dordrecht: Kluwer Academic Publishers.

- Owens, D. 2000. Reason Without Freedom: The Problem of Epistemic Normativity. London and New York: Routledge.

- Owens, D. 2006. Testimony and assertion. Philosophical Studies 130: 105-129.

- Owens, D. Forthcoming. Human testimony. In his Normativity and Control. Oxford University Press.

- Schmitt, F. 2006. Testimonial justification and transindividual reasons. In The Epistemology of Testimony, ed. J. Lackey and E. Sosa, 193-224. New York: Oxford University Press.

- Schroeder, M. 2012. Stakes, withholding, and pragmatic encroachment on knowledge. Philosophical Studies 160: 265-285.

- Stanley, J. and Hawthorne, J. 2008. Knowledge and action. Journal of Philosophy. 105: 571590.

- Welbourne, M. 1986. The Community of Knowledge. Elsevier Science Ltd.

- Williamson, T. 2000. Knowledge and its Limits. Oxford: Clarendon Press.

- Wright, S. 2014. The Nature of Testimonial Justification. PhD Thesis. University of Sheffield.

- Wright, S. 2016. The transmission of knowledge and justification. Synthese 193: 293-331.

13 For immensely helpful comments, advice, and discussion we would like to thank Dan Baras, David Enoch, Stephen Wright, and two anonymous referees for this journal. 